\section{As estratégias argumentativas do regime militar em Atos Institucionais*}

\author{
The argumentative strategies \\ of the military regime in \\ Institutional Acts
}

Ana Paula SANTOS DE OLIVEIRA (UFAL) virtual.ana@gmail.com

Recebido em: 12 de abr. de 2020. Aceito em: 12 de maio de 2020.

*Estudo realizado no Instituto de Linguística da Universidade de Buenos Aires (UBA), sob a orientação da profa. Dra. Alejandra Vitale, com o financiamento da Coordenação de Aperfeiçoamento de Pessoal de Nível Superior (CAPES) - Programa de Doutorado Sanduíche no Exterior (PDSE).
SANTOS DE OLIVEIRA, Ana Paula. As estratégias argumentativas do regime militar em Atos Institucionais. Entrepalavras, Fortaleza, V. 10, n. 2, e1871, p. 1-19, maio-ago/2020. DOI: 10.22168/2237-6321-21871.

Resumo: Com o objetivo de desvelar as principais estratégias argumentativas utilizadas pela ditadura militar brasileira (1964-85) a partir de seus 17 Atos Institucionais (AIs), este estudo se ancora na Teoria da argumentação, desde a Nova retórica (PERELMAN; TYTECA, 2005), e na Análise de Discurso de filiação pecheutiana (PÊCHEUX, 1988; ORLANDI, 2012; COURTINE, 2019; INDURSKY, 2013). Nessa perspectiva, a análise do corpus se direciona para a dimensão argumentativa das memórias discursivas (VITALE, 2015), cujos mecanismos têm a função de provocar a adesão a determinados dizeres. Seus resultados indicam que o Estado militar recorreu à estratégia da definição ao nomear a destituição do presidente João Goulart de autêntica revolução, afastando, com isso, a ideia de ação ilegítima, além de ter utilizado a técnica de inclusão da parte no todo, por meio da qual apresenta a tomada do poder como um movimento civil-militar, e a de vínculo causal, quando justifica a ação como necessária para salvar o Brasil do comunismo. As análises apontam ainda para uma série de deslizamentos de sentidos, o que comprova que a língua funciona na tensão entre o mesmo e o diferente, sob a determinação da processualidade histórica, refletida na materialidade discursiva.

Palavras-chave: Estratégias argumentativas. Estado militar. Memória discursiva. 
V. $10(2)$

1-19

maio-ago

2020

Abstract: With the objective of unveiling the main argumentative strategies used by the Brazilian military dictatorship (1964-85) from its 17 Institutional Acts (AIs), this study is based on the Theory of argumentation (PERELMAN; TYTECA, 2005), since the New rhetoric (PERELMAN; TYTECA, 2005), and in the Pecheuxtian Discourse Analysis (PÊCHEUX, 1988; ORLANDI, 2012; COURTINE, 2019; INDURSKY, 2013). From this perspective, the analysis of the corpus is directed to the argumentative dimension of discursive memories (VITALE, 2015), whose mechanisms have the function of provoking adherence to certain sayings. Their results indicate that the military state resorted to the strategy of definition by appoint the removal of President João Goulart of authentic revolution, thus distancing the idea of illegitimate action, besides having used the technique of inclusion of the part in the whole, through which it presents the taking of power as a civil-military movement, and that of causal link when it justifies the action as necessary to save Brazil from communism. The analyses also point to a series of slips of meanings, which proves that the language works in the tension between the same and the different, under the determination of historical procedurally, reflected in the discursive materiality.

Keywords: Argumentative strategies. Military state. Discursive memory.

\section{Introdução}

A discursividade que envolve o Estado militar brasileiro (1964-85) antecede a sua própria instauração, pois remete a uma memória que se vincula a uma posição sujeito que, desde que os movimentos de esquerda começaram a ter maior visibilidade, sobretudo a partir da revolução de 1917, atua no sentido de elaborar estratégias discursivas para convencer a massa a repudiar as ideologias contra-hegemônicas.

No Brasil, a representação do comunismo e dos comunistas pela ideologia hegemônica foi impulsionada, sobretudo, pelos jornais impressos 50 anos antes da ação militar de 1964, tendo importante atuação na (re)produção de dizeres que negativavam as ideias marxistas.

Considerando que todo governo busca legitimidade, utilizando, para isso, mecanismos de persuasão, este estudo se direciona para as estratégias argumentativas mais recorrentes nos preâmbulos dos 17 Atos Institucionais (AIs) promulgados pelos militares após a destituição de João Goulart da Presidência da República, em 31 de março de 1964.

Como justificativa, os militares e seus apoiadores reproduziam o discurso de que o governo de Goulart estava conduzindo o Brasil para o comunismo, por isso a necessidade da tomada do poder. Trata-se de uma narrativa que se vincula a uma rede de memória cujos enunciados haviam se transformado em lugar comum entre os brasileiros em 1964. 
Tendo em vista que a memória discursiva remete "à existência histórica do enunciado no interior de práticas discursivas regradas por aparelhos ideológicos", conforme Courtine (2009, p. 105106), é importante lembrar que, além da grande imprensa, os setores conservadores, como a igreja católica, atuaram na circulação dos dizeres em análise, com o apoio determinante da elite econômica e dos poderes constituídos.

Em síntese, este estudo se volta para a dimensão argumentativa dessa memória (VITALE, 2015), partindo do princípio de que a linguagem funciona na tensão entre o mesmo e o diferente. Isto é, em todo dizer há sempre algo que se mantém e que produz deslocamento de sentidos, diz Orlandi (2012a). É a partir dessa tensão que buscamos compreender as estratégias utilizadas no discurso militar para convencer os brasileiros da necessidade da ruptura da ordem institucional no país em 1964.

\section{A dimensão argumentativa nos estudos discursivos}

Este estudo tem seu marco teórico e metodológico ancorado no diálogo entre a Teoria da argumentação, mais especificamente na Nova retórica, através dos estudos de Perelman e Olbrechts-Tyteca (2005), e a Análise do Discurso de viés Pecheutiano, através de autores como Pêcheux (1988), Orlandi (2012), Courtine (2009) e Indursky (2013).

Em primeiro lugar, é necessário destacar que todo e qualquer discurso tem uma dimensão argumentativa. De acordo com Fiorin (2016), a argumentação está intrinsecamente relacionada à vida em sociedade, especialmente a partir das primeiras democracias, quando o uso da força física para a resolução de problemas foi dando lugar ao uso da palavra para persuadir os outros a fazerem ou deixarem de fazer algo.

Ainda segundo o autor:

Se a sociedade é dividida em grupos sociais, com interesses divergentes, então os discursos são sempre o espaço privilegiado de luta entre vozes sociais, o que significa que são precipuamente o lugar de contradição, ou seja, da argumentação, pois a base de toda a dialética é a exposição de uma tese e sua refutação. (FIORIN, 2015, p. 9).

Em meio a esse embate de palavras, cuja essência está ligada à defesa de interesses dentro de uma sociedade dividida em classes, sob a evidência da igualdade de direitos e de deveres, os estudos em torno da retórica ganharam novo patamar em 1958, com a publicação de Tratado de argumentação: a nova retórica, de Perelman e Olbrechts-Tyteca. 
V. $10(2)$

1-19

maio-ago

2020

Ao se contrapor à concepção cartesiana de razão e de raciocínio, a obra busca recuperar os postulados da retórica e da dialética na análise argumentativa (PLANTIN, 2002), originando um novo campo do saber - a Nova retórica. Com o tratado, Perelman e Olbrechts-Tyteca (2015), ao dar status metodológico à argumentação teórica, tomam como fundamento um conjunto de ferramentas/estratégias discursivas do qual se serve o orador para persuadir e convencer seus interlocutores (NARVÁEZ, 2019).

A respeito da relação estabelecida entre os atores sociais no ato argumentativo, Perelman (1987) é elucidativo ao apontar que:

A argumentação é essencialmente comunicação, diálogo, discussão. Enquanto a demonstração é independente de qualquer sujeito, até mesmo do orador, uma vez que um cálculo pode ser efetuado por uma máquina, a argumentação por sua vez necessita que se estabeleça um contacto entre o orador que deseja convencer e o auditório disposto a escutar. (PERELMAN, 1987, p. 235).

Com base nos postulados da Nova retórica, esta pesquisa tem como objeto de análise uma rede de memória construída décadas antes de sua atualização no pós-golpe de 1964, formando parte do imaginário do brasileiro. De outra forma, seu emprego não se deu por casualidade, no calor do momento, sendo antes uma ação planejada com vistas a um fim, a saber: persuadir os brasileiros a apoiarem a ação de 1964 .

Para investigar essa rede de memória, mobilizamos a categoria de memória discursiva, que indica que "toda produção discursiva que se efetua nas condições determinadas de uma conjuntura movimenta faz circular - formulações anteriores, já enunciadas", segundo Courtine (2009, p. 104), que vincula essa memória à relação do interdiscurso com o intradiscurso, através da qual "uma formulação-origem retorna na atualidade de uma 'conjuntura discursiva", processo que ele designa de efeito-de-memória.

Acerca do interdiscurso, o seu efeito funciona pelo esquecimento de formulações já realizadas que determinam o que dizemos.

É preciso que o que foi dito por um sujeito específico em um momento particular se apague na memória para que, passando para o 'anonimato', possa fazer sentidos em 'minhas' palavras. (ORLANDI, 2012a, p. 33-34).

Em suma, enquanto o interdiscurso é o lugar de construção do pré-construído (construção anterior, independente ao que é construído 
na enunciação), fornecendo "os objetos dos quais a enunciação se apropria" (COURTINE, 2009, p. 75), o intradiscurso, por outro lado, corresponde ao espaço da formulação de uma sequência linguística específica, onde o sujeito intervém, estando as duas categorias articuladas na produção de sentidos, na condição de dimensões constitutivas do discurso.

No espaço de formulação foco deste estudo, constituído dos Atos Institucionais (AIs) promulgados pelas forças militares nos cinco primeiros anos do regime militar brasileiro, consideramos a dimensão argumentativa das memórias discursivas, a que Vitale (2015) cunha a noção de memória retórico-argumentativa para se dirigir às estratégias empregadas em um discurso para alcançar a adesão a uma determinada tese.

Em seu estudo acerca das estratégias usadas pela imprensa escrita da Argentina por ocasião da instauração dos sucessivos golpes de Estado no país entre 1930 e 1976 para convencer os argentinos da necessidade de rompimento institucional, Vitale (2015) parte da teoria da argumentação, desde a Nova retórica, inscrevendo-a no interior dos estudos discursivos, em específico, da Análise do Discurso Francesa.

Para isso, a estudiosa ajustou os estudos da Retórica a fim de possibilitar o diálogo entre as duas áreas do conhecimento, dado que, diferente do que apontam os estudos discursivos iniciados por Pêcheux em 1969, para a retórica, os sentidos são determinados pelo sujeito. Em lugar desse sujeito consciente, soberano, Vitale (2015) se reporta às posições da imprensa golpista da Argentina como inerentes às memórias retórico-argumentativas vinculadas a determinadas posições ideológicas.

Nessa perspectiva, Pêcheux (1988, p. 160) aponta que o caráter material do sentido, "mascarado por sua evidência transparente para o sujeito" (intradiscurso), consiste na sua dependência constitutiva com "o todo complexo com dominante das formações ideológicas" (interdiscurso).

Para o teórico, da relação do sujeito com o já dito e o seu dizer decorrem dois tipos de esquecimentos. Enquanto o esquecimento $n^{0}$ 2, da ordem da enunciação, leva à ilusão do controle do dizer, levando o sujeito a acreditar que há uma relação direta entre pensamento, linguagem e mundo, o esquecimento $\mathrm{n}^{\mathrm{0}} 1$, da ordem do ideológico, leva-o a "esquecer" o vínculo entre história e enunciação ao acreditar que é a origem de seu dizer. De outra forma, o sujeito não tem consciência de que é interpelado. 
V. $10(2)$

1-19

maio-ago

2020

Operando de forma articulada, os dois esquecimentos permitem ao sujeito - de forma inconsciente, por meio da determinação ideológica - produzir sentidos pelo retorno à memória discursiva, através da qual há a retomada de pré-construídos, no espaço entre o silêncio e a linguagem.

Após delimitarmos o marco teórico que fundamenta este estudo, o próximo tópico se direciona para a análise do seu corpus de pesquisa, constituído de 14 materialidades discursivas retiradas dos preâmbulos dos Atos Institucionais (AIs) promulgados pelo Estado militar brasileiro entre 1964 e 1969. Como base metodológica, em nosso percurso de análise, mobilizamos conceitos da Análise do Discurso Francesa e da Teoria da argumentação, com ênfase nas estratégias discursivas utilizadas nos AIs.

\section{As estratégias argumentativas nos AIs do período militar}

Com a chegada ao poder, as forças militares e seus apoiadores logo se apressaram em justificá-la. O primeiro passo foi nomeá-la. Assim, buscavam afastar outros gestos de interpretação para o acontecimento. Para isso, recorreram à estratégia argumentativa vinculada à definição.

De acordo com Fiorin (2016), trata-se de argumento fundado no princípio da identidade, dependendo o seu modo dos fins pretendidos. Em outras palavras, as definições impõem um determinado sentido, com o propósito de convencer o interlocutor de que determinado significado é o único que deve ser considerado.

A isso, acrescentamos, a partir da Análise do Discurso Francesa, que o sentido de um objeto não está dado previamente, pois depende da posição do sujeito no jogo discursivo. Nessa perspectiva, vemos o discurso como objeto sócio-histórico. Assim, partimos das condições de produção de 1964 para destacar que, tão logo João Goulart fora destituído, os militares recorreram à estratégia de definição para justificar o evento.

A sequência discursiva (SD) abaixo destaca essa finalidade:

SD1 - É indispensável fixar o conceito do movimento civil e militar que acaba de abrir ao Brasil uma nova perspectiva sobre o seu futuro. O que houve e continuará a haver neste momento, não só no espírito e no comportamento das classes armadas, como na opinião pública nacional, é uma autêntica revolução. (AI-1, 9 de abril de 1964 [grifo nosso]). 
A primeira definição apresentada pela SD1, movimento civil e militar, visa garantir que a ação militar não se deu de modo unilateral, ou seja, por iniciativa apenas das forças militares. Trata-se de uma estratégia utilizada pelos militares para convencer os brasileiros de que a nova situação, na medida em que contou com a participação da sociedade em sua totalidade, surgiu de um movimento democrático.

Com isso, dava-se um caráter de legalidade ao acontecimento. O uso do sintagma autêntica revolução, que incide na segunda definição, reforça essa perspectiva, afastando, consequentemente, a ideia de que o evento fora inautêntico, ou destituído de legitimidade.

Ainda com relação à SD1, podemos notar o emprego do que a Nova retórica denomina de estratégia de inclusão da parte no todo, que engloba dois grupos de argumentos, a saber, os que demonstram a inclusão das partes num todo e os que demonstram a divisão do todo em suas partes, de acordo com Perelman e Olbrechts-Tyteca (2005).

Voltando-se para o primeiro tipo de inclusão, que objetiva tratar as partes agrupadas de forma igualitária, não lhes atribuindo qualidades particulares, a SD1 vincula dois grupos - militares/classes armadas, de um lado, e sociedade civil/opinião pública, de outro -, evidenciando, pois, uma equidade de participação, como acentuam os conectores aditivos e e não só...como, entre elementos que exercem distintos papéis na sociedade.

Em vista do peso da ação de 31 de março, visto que ocasionou a destituição de um governo constitucional, isto é, dotado de legitimidade, as promessas de um futuro promissor para o Brasil, lugar comum no discurso político, ganharam força no regime que então se iniciava, que, ao evidenciar a ruptura com a ordem anterior, destaca que o acontecimento abriu ao Brasil uma nova perspectiva sobre o seu futuro (SD1).

Recorrente no discurso militar, a justificativa de que a deposição de João Goulart fora necessária para salvar o país do comunismo é quase sempre acompanhada do argumento de que a ação que desencadeou a tomada do poder contou com o apoio da sociedade civil brasileira.

A SD1 aponta nessa direção ao usar a estratégia de dissociação das noções, que, conforme Perelman e Olbrechts-Tyteca (2005, p. 468), "pressupõe a unidade primitiva dos elementos confundidos no seio de uma mesma concepção, designados por uma mesma noção". Assim, quando destaca que a tomada do poder é uma autêntica revolução, indica, de modo implícito, a existência de uma segunda revolução - a inautêntica. 
V. $10(2)$

1-19

maio-ago

2020

Nessa perspectiva, se a primeira revolução (a autêntica) é projetada como legítima, posto que defensora da vontade da nação, a última é representada como ilegítima. Com isso, o enunciado estabelece uma contraposição ao governo Goulart, representado por seus opositores como um governo de tendência comunista em vista da proximidade com a classe trabalhadora e pelas reformas estruturais que buscava aprovar.

Logo, é válido afirmar que, ao definir o acontecimento de 31 março de autêntica revolução, o discurso militar se opunha a outra revolução, a da esquerda, representada como inautêntica, dentro de um contexto mundial marcado pelo fortalecimento dos movimentos contra-hegemônicos, desencadeados pelas Revoluções Russa (1917) e Cubana (1959), num cenário de forte tensão, que culminou na Guerra fria.

Aqui, é possível observar mais de perto o vínculo da linguagem e da história, estando a primeira inserida no processo sócio-histórico, sem o qual não há produção de sentidos. O efeito da exterioridade na língua, afirma Orlandi (2012b, p. 39), viabiliza a relação discursiva real/realidade, "sendo o real função das determinações históricas que constituem as condições de produção materiais e a realidade a relação imaginária dos sujeitos com essas determinações", refletindo na significação do dizer.

Utilizado desde os primeiros momentos do regime militar, o argumento de inclusão da parte no todo sofre um deslizamento de sentido ainda no primeiro Ato Institucional, quando as forças militares destacam a existência de movimentos que se contrapõem à nova situação, assim como delimitam as posições dos militares e do povo no regime:

\section{SD2 - A revolução se distingue de outros movimentos armados} pelo fato de que nela se traduz, não o interesse e a vontade de um grupo, mas o interesse e a vontade da Nação. (AI-1, 9 de abril de 1964 [grifo nosso]).

SD3 - Os Chefes da revolução vitoriosa, graças à ação das Forças Armadas e ao apoio inequívoco da Nação, representam o Povo e em seu nome exercem o Poder Constituinte, de que o Povo é o único titular. (AI-1, 9 de abril de 1964 [grifo nosso]).

Ao sinalizar a existência de grupos opositores ao regime, quando se refere aos outros movimentos armados, a SD2 evidencia 
que a ação militar não contava com apoio total da sociedade, ainda que destaque que tais movimentos são formados por uma minoria atendia ao interesse e à vontade de um grupo. Com isso, minimiza a sua importância.

Por outro lado, os defensores da nova situação, que atendiam ao interesse e à vontade da Nação, são representados como o grupo mais amplo, que corresponderia a uma nação. Nesse jogo de palavras, apaga-se o apoio da nação (ou dos brasileiros) ao governo de João Goulart, destituindo-o, dessa forma, de representatividade junto aos brasileiros.

Na SD3, a menção ao termo Nação explicita uma relação hierárquica entre os atores que apoiaram a destituição de Goulart, o que indica um efeito de sentido contrário ao que evidenciam a SD1 e a SD2. A partir das condições de produção que propiciaram a ação de 1964, pode-se inferir que o léxico se refere apenas a uma parte da sociedade.

Analisando as SDs, quatro grupos apoiam o regime: os Chefes da revolução vitoriosa, as Forças armadas, a Nação e o Povo.

Embora o então presidente da câmara dos deputados, Ranieri Mazzilli, tenha assumido interinamente a Presidência da República após a ação militar, como previa a Constituição Federal de 1946, o comando do Brasil estava, em verdade, nas mãos de uma junta militar, composta pelo brigadeiro Francisco de Assis Correia de Melo, pelo vice-almirante Augusto Rademaker e pelo general Artur da Costa e Silva (NETTO, 2014).

Essa junta, nomeada de Comando supremo da revolução, com os seus integrantes sendo denominados de chefes da revolução vitoriosa (SD3), funcionou até a eleição indireta que elegeu o marechal Castello Branco o primeiro presidente da ditadura militar no Brasil, duas semanas após a derrubada de Goulart da Presidência da República (NETTO, 2014).

Ainda sobre a SD3, a divergência de sentidos entre os léxicos Nação e Povo, embora implícita, é reveladora de uma formação social marcada pela desigualdade social. Para entendê-la, é necessário conhecer os atores sociais que agiram às vésperas daquele 31 de março.

É preciso saber que se, de um lado, as forças militares tiveram o apoio da elite econômica, dos setores conservadores, como a igreja católica, dos meios de comunicação de massa e da classe média, de outro, a situação anterior tinha a sua imagem atrelada aos mais pobres.

Para entender como grupos sociais tão díspares, como as classes alta e média, uniram-se no apoio aos militares, é necessário saber que os sentidos são determinados pelas Formações Ideológicas 
V. $10(2)$

1-19

maio-ago

2020

- organizações complexas de atitudes e representações ligadas às posições de classes em conflitos -, e que as condições ideológicas tanto propiciam a reprodução como a transformação das relações de produção (PÊCHEUX, 1988).

É um erro localizar em pontos diferentes o que contribuiria para a reprodução e a transformação dessas relações, ressalta Pêcheux (1988), pois o sujeito, independente de sua classe, é estimulado a se identificar com a ideologia dominante em uma formação social capitalista.

Trata-se de uma posição servil, ainda que o sujeito não se dê conta dessa condição, na medida em que a ideologia o dota de consciência para que acredite que as suas ideias provêm de sua escolha, não de uma determinação exterior (ALTHUSSER, 1985).

A respeito do item lexical povo, Indursky (2013), ao analisar a construção discursiva do outro no discurso dos cinco presidentes militares (1964-85), aponta que o termo não é representado como entidade global, sendo o seu emprego partitivo, ora se referindo à classe média, à classe produtora, às formas militares, à classe trabalhadora, à coletividade dos brasileiros, à sociedade civil organizada, ora à massa de manobra política.

Em suas análises, a autora constatou diferenças de tratamento dos cinco presidentes aos diferentes grupos sociais; sobretudo, entre os apoiadores do regime e os trabalhadores. Assim, distinto dos primeiros, o grupo formado pela classe trabalhadora é representado como aquele convocado a se sacrificar pela nação, a primeiro esperar o bolo econômico crescer antes de usufruir de seus ganhos, garantidos pelo regime.

Referindo-se aos protestos contra o governo de João Goulart, às vésperas de sua deposição, que contou com a presença da classe média, da igreja católica, com o apoio da classe econômica e de partidos políticos conservadores, Indursky (2013, p. 126) destaca que, a despeito de suas origens, essas manifestações assumem, no discurso militar pós-golpe, "as características de uma procuração oficial passada pelo povo aos militares", que, desse modo, agem e falam como seu portavoz autorizado.

Silenciada, a voz da classe trabalhadora foi substituída por um "simulacro de voz do povo", assinala Indursky (2013, p. 130), tendo em vista que ao povo é atribuído um discurso, que, em verdade, pertence aos presidentes militares, "um simples mediador que se outorgou tal direito e atua como um ventríloquo", complementa a autora. 
Considerando as análises de Indursky e o corpus discursivo deste estudo, nota-se que o discurso militar recorre ao argumento pragmático, a partir do qual se aprecia "um ato ou um acontecimento consoante suas consequências favoráveis ou desfavoráveis" (PERELMAN; OLBRECHTSTYTECA, 2005, p. 303), para convencer os trabalhadores a se sacrificarem pelo país em troca de uma promessa de progresso. Vale observar que o uso desse argumento não requer justificativa para ser aceita pelo senso comum. As consequências que apontam podem ser cabais ou hipotéticas.

A promessa de um futuro melhor é recorrente no discurso militar pós-golpe, como mostram as sequências a seguir:

SD1 - É indispensável fixar o conceito do movimento civil e militar que acaba de abrir ao Brasil uma nova perspectiva sobre o seu futuro. (AI-1, 9 de abril de 1964 [grifo nosso]).

SD4 - Em nome da revolução vitoriosa, e no intuito de consolidar a sua vitória, de maneira a assegurar a realização dos seus objetivos e garantir ao País um governo capaz de atender aos anseios do povo brasileiro, o Comando Supremo da Revolução, representado pelos Comandantes-em-Chefe do Exército, da Marinha e da Aeronáutica resolve editar o seguinte. (AI-1, 9 de abril de 1964 [grifo nosso]).

SD5 - A revolução está viva e não retrocede. Tem promovido reformas e vai continuar a empreendê-las, insistindo patrioticamente em seus propósitos de recuperação econômica, financeira, política e moral do Brasil. (AI-2, 27 de outubro de 1965 [grifo nosso]).

Perelman e Olbrechts-Tyteca (2005) observam que, mesmo se impondo de modo incontestável, o acontecimento é levado a ser situado em um contexto que o explique. Daí a necessidade de justificar a tomada do poder pelos militares, seja ambientando-a em uma aliança civil-militar para salvar o Brasil, seja culpando Goulart pela crise econômica e política instalada em seu governo, além de lançar promessas de progresso.

É o que trazem as três sequências em análise quando associam a deposição do presidente João Goulart a uma nova perspectiva sobre o seu futuro (do país) (SD1); para garantir ao País um governo capaz de atender aos anseios do povo brasileiro ( $\mathrm{SD}_{4}$ ); e à recuperação econômica, financeira, política e moral do Brasil (SD5). 
V. $10(2)$

1-19

maio-ago

2020

Nesse sentido, quando as SDs 4 e 5 destacam que a revolução garantiria ao país um governo capaz de atender aos anseios do povo brasileiro e sua recuperação econômica, financeira, política e moral, deixa implícito que, além de não atender às expectativas do povo, o governo Goulart fora o responsável pela desordem econômica, política e moral instalada no Brasil. Dessa forma, silenciam a forte pressão, interna e externa, sofrida por Goulart mesmo antes de assumir a presidência.

Abaixo, relacionamos outras SDs que reforçam esse discurso:

SD6 - A Revolução é um movimento que veio da inspiração do povo brasileiro para atender às suas aspirações mais legítimas: erradicar uma situação e um Governo que afundavam o País na corrupção e na subversão. (AI-2, 27 de outubro de 1965 [grifo nosso]).

SD7 - Não se pode desconstituir a revolução, implantada para restabelecer a paz, promover o bem-estar do povo e preservar a honra nacional. (AI-2, 27 de outubro de 1965 [grifo nosso]).

Na SD6, os militares são ainda mais enfáticos ao associarem o governo Goulart à corrupção e à subversão. Assim, reafirmam a ligação entre a tomada do poder e a necessidade de salvar o Brasil da ameaça comunista. Desse modo, percebe-se uma transferência de valores entre os elementos da cadeia causal que parte do efeito à causa. De outro modo, o regime militar seria um efeito da tensão provocada pela situação anterior. Com isso, ao transferir para João Goulart a responsabilidade pela própria queda, afastava-se a ideia de ilegalidade da ação militar.

A sequência em análise pode ser referida ainda ao argumento da direção, que responde à pergunta "aonde se quer chegar?" (PERELMAN; OLBRECHTS-TYTECA, 2005, p. 321), quando aponta que a revolução tem o propósito de erradicar uma situação e um Governo que afundavam o País na corrupção e na subversão. Assim, o discurso militar procura convencer os brasileiros de que o regime teria uma meta a cumprir e que, para alcançá-la, precisaria ter continuidade. Ao mesmo tempo, sinaliza, de modo implícito, para os efeitos decorrentes da não intervenção militar no governo anterior: o aprofundamento da corrupção e da subversão. Com isso, ressalta a inevitabilidade das ações desencadeadas no ano anterior.

Na SD seguinte, esse quadro é acentuado quando o governo 
militar aponta que Não se pode desconstituir a revolução, inferindo-se daí que, um ano e meio após o golpe, o regime não havia se consolidado. Novamente, recorre-se à crítica ao governo Goulart para justificar a sua deposição. Junto a isso, faz-se uso de um advérbio de negação (não) para enfatizar a necessidade da continuidade do regime militar.

Como na sequência que a antecede, a SD7 estabelece uma transferência de valor entre efeito e causa, apontando a perda da paz, a falta de bem-estar e a ausência de honra como fatores desencadeadores da ação militar que culminou na derrubada do governo Goulart.

Falando em nome do povo, o regime retoma a estratégia da dissociação das noções para desqualificar o governo anterior:

SD8 - [...] a Revolução Brasileira de 31 de março de 1964 teve, conforme decorre dos Atos com os quais se institucionalizou, fundamentos e propósitos que visavam a dar ao País um regime que, atendendo às exigências de um sistema jurídico e político, assegurasse autêntica ordem democrática, baseada na liberdade, no respeito à dignidade da pessoa humana, no combate à subversão e às ideologias contrárias às tradições de nosso povo, na luta contra a corrupção. (AI-5, 13 de dezembro de 1968 [grifo nosso]).

Ao garantir que a deposição de Goulart buscava assegurar ao país uma autêntica ordem democrática, a sequência em análise faz uso da estratégia da dissociação das noções ao deixar implícito que a democracia carecia de autenticidade com Goulart, ou seja, que não havia democracia. Em seguida, traz elementos caracterizadores da democracia - a liberdade, o respeito à dignidade da pessoa humana, o combate à subversão e a ideologias e a luta contra a corrupção. Tratase, pois, de uma construção discursiva que busca reforçar a expressão autêntica revolução, da SD1.

Promulgada quase cinco anos após a deposição de Goulart, o AI-5, a qual pertence a SD8, reforça o uso do aparelho repressor do Estado pelo governo militar, então sob a presidência do marechal Costa e Silva, cerceando ainda mais a liberdade e o respeito à dignidade da pessoa humana, ao contrário do que demonstra a sequência. O que estava em curso era, em verdade, o combate ao que o Estado militar denominava de subversão e ideologias contrárias às tradições de nosso povo, que culminavam na perseguição aos opositores do regime militar. 
V. $10(2)$

1-19

maio-ago 2020

O emprego da estratégia de valorização dos fins foi recorrente nos primeiros anos da ditadura, como vimos nas sequências já analisadas. "Nele, os fins justificam os meios", pontua Fiorin (2016, p. 165).

Para funcionar, os fins devem interagir com os meios, explicam Perelman e Olbrechts-Tyteca (2005), que apontam que, quando um dado fim não é atingido, é comum se recorrer ao discurso de que os bons meios foram ignorados ou não se teve o cuidado necessário. Nas SDs abaixo, relacionamos trechos de AIs de diferentes momentos do regime a fim de analisar como funciona o discurso sobre os meios ante os fins propostos:

SD9 - O Ato Institucional que é hoje editado [...] se destina a assegurar ao novo governo a ser instituído os meios indispensáveis à obra de reconstrução econômica, financeira, política e moral do Brasil, de maneira a poder enfrentar, de modo direto e imediato, os graves e urgentes problemas de que depende a restauração da ordem interna e do prestígio internacional da nossa Pátria. (AI-1, 9 de abril de 1964 [grifo nosso]).

SD10 - [...] se torna imperiosa a adoção de medidas que impeçam sejam frustrados os ideais superiores da Revolução, preservando a ordem, a segurança, a tranquilidade, o desenvolvimento econômico e cultural e a harmonia política e social do País comprometidos por processos subversivos e de guerra revolucionária. (AI-5, 13 de dezembro de 1968 [grifo nosso]).

Entre 9 de abril de 1964 e 13 de dezembro de 1968, datas de promulgação do primeiro e do quinto AIs, respectivamente, a repressão estatal no Brasil aumentou consideravelmente (NETTO, 2014). Nas duas sequências relacionadas, esse cenário é evidenciado quando abordam a necessidade de medidas para levar adiante os objetivos "revolucionários".

Assim, enquanto o SD9 destaca que seu conteúdo se destina a garantir ao regime os meios indispensáveis à obra de reconstrução econômica, financeira, política e moral do Brasil, a SD10 destaca, em tom mais autoritário, que é imperiosa a adoção de medidas que impeçam sejam frustrados os ideais superiores da Revolução. 
A SD10 sinaliza, pois, um desvio de sentido em relação ao que foi apresentado nos AIs anteriores, pois explicita a crise instalada no país após a deposição de Goulart. Por crise, entenda-se resistência ao regime militar. Resistência possibilitada pelo próprio Estado, a partir do qual o sujeito sofre diferentes processos de individualização e de socialização, que derivam de diferentes formas de poder (ACHARD et al., 2015).

As instituições e o Poder constituído exercem papel determinante nesse sentido, afirmam Achard et al. (2015, p. 55), que acrescentam que "é nessa instância que se dão as lutas, os confrontos e onde podemos observar os mecanismos de imposição, de exclusão e de resistência".

Além dos meios que visavam o progresso do país, as forças militares deram visibilidade às dificuldades para alcançar o que nomeavam de ideais superiores (SD10), em virtude da resistência que vinham sofrendo, inclusive de antigos defensores. Com isso, justificam o emprego de meios de combate cada vez mais violentos pelo Estado.

Desde os primeiros momentos do regime, os militares agiram na ilegalidade, com perseguições, sequestros, prisões clandestinas, torturas e assassinatos de militantes de esquerda, adversários políticos, religiosos, trabalhadores, estudantes, muitos dos quais estão desaparecidos até hoje, chegando-se a banir brasileiros do país, numa etapa mais repressiva.

Ao mesmo tempo, recorriam ao poder judiciário para elaborar leis mais autoritárias, reformulando e extinguindo outras nesse sentido. Contudo, oficialmente, o governo militar tentava se posicionar na condição de Estado democrático de direito. É o que evidenciam as SDs abaixo:

SD11 - [...] as pessoas atingidas pelas sanções políticas e administrativas do processo revolucionário devem ter igualdade de tratamento sob o império das normas institucionais e demais regras legais delas decorrentes. (AI- $6,1^{\circ}$ de fevereiro de 1969 [grifo nosso]).

SD12 - Considerando que se impõe, também, a determinação de normas uniformes a serem impostas a todos quantos, servidores públicos, ou não, hajam sido ou venham a ser atingidos pelas disposições dos Atos Institucionais editados, entre outros motivos, com a finalidade de preservar os ideais e princípios da Revolução de 31 de março de 1964 e assegurar a continuidade da obra revolucionária (AI-10, 16 de maio de 1969 [grifo nosso]). 
V. $10(2)$

1-19

maio-ago

2020

Ao garantir o respeito à igualdade de tratamento às pessoas acusadas de delitos, como é possível apreender das duas sequências, os militares recorrem ao argumento da semelhança, ou da regra da justiça, que tem como base de funcionamento o princípio de identidade, pelo qual se defende a aplicação de uma mesma regra a uma mesma situação.

O argumento da semelhança "é contrária à lógica do privilégio", nas palavras de Fiorin (2016, p. 134). Com isso, o discurso militar silencia as ilegalidades cometidas pelo Estado militar, ou a ruptura com a ordem democrática. "As palavras são cheias de sentidos a não dizer e, além disso, colocamos no sentido muitas delas", assinala Orlandi (2007, p. 14).

Na prática, os processos judiciais conduzidos pelo regime não seguiam os critérios de um Estado democrático, como a garantia a uma defesa ampla e imparcial. Nesse sentido, o artigo $4^{\circ}$ do AI- 5 assegurava ao presidente da república, depois de ouvido o Conselho de Segurança Nacional, "sem as limitações previstas na constituição federal", suspender os direitos políticos de qualquer pessoa e cassar mandatos eletivos.

Logo, constatam-se desvios de sentidos entre a SD11 e a SD12 e o que é estabelecido em lei pelo Estado militar, estando os dois discursos distantes do que ocorriam na prática, nos porões da ditadura.

Através da análise do corpus discursivo em estudo, é possível chegar ao entendimento de que a dificuldade das forças militares em dar continuidade ao projeto iniciado em 1964, intensifica-se em 1969, último ano de publicação dos AIs. Com isso, a violência do regime militar atinge o seu ápice com o AI-14, que prevê a mudança na Constituição Federal de 1967 para estabelecer a pena de morte, a prisão perpétua e o banimento do país em caso de guerra revolucionária ou subversiva.

Relacionamos duas sequências do AI-14 que refletem esse clima:

SD13 - Considerando que atos de guerra psicológica adversa e de guerra revolucionária ou subversiva, que atualmente perturbam a vida do País e o mantém em clima de intranqüilidade e agitação, devem merecer mais severa repressão; (AI-14, 5 de setembro de 1969 [grifo nosso]).

SD14 - Considerando que aqueles atos atingem, mais profundamente, a segurança nacional, pela qual respondem todas as pessoas naturais e jurídicas, devendo ser preservada para o bem-estar do povo e desenvolvimento pacifico das atividades do País, resolvem editar o seguinte Ato Institucional: (AI-14, 5 de setembro de 1969 [grifo nosso]). 
Considerando as duas SDs, é válido retomar a discussão sobre a validade dos fins em detrimento dos meios empregados para alcançá-los. A esse respeito, Perelman e Olbrechts-Tyteca (2005, p. 315) afirmam que ainda que o fim valorize os meios, nem sempre os justifica, tendo em vista que "o uso destes pode ser condenável em si, ou ter consequências desastrosas, cuja importância pode ultrapassar a do fim buscado".

Mesmo assim, continuam os autores, um fim convertido em crime, que, em outras situações, costuma ser condenado, poderá ser considerado nobre, diminuindo a sua repulsa.

[...] o assassínio político, o crime do idealista, mesmo quando são punidos com mais severidade do que o crime crapuloso, não são objeto de uma condenação moral sem reticências (PERELMAN E OLBRECHTS-TYTECA, 2005, p. 315).

Na SD14, o discurso militar retoma a estratégia da inclusão da parte no todo ao indicar que todas as pessoas que tenham cometido atos subversivos sofreriam penalidades. Dessa forma, busca convencer os brasileiros de que o bem-estar do povo e desenvolvimento pacífico das atividades do País se sobrepõem a toda e qualquer subjetividade, ou interesses representados como não coletivos pelos militares.

Com isso, retoma-se uma memória discursiva presente no início da ditadura, e que "irrompe na atualidade do acontecimento" (COURTINE, 2009, p. 103) em forma de pré-construídos, a exemplo do que indica a SD4 quando representa o Estado militar como capaz de atender aos anseios do povo brasileiro. Tudo seria em nome do povo e para o povo.

Assim, silencia-se que a classe trabalhadora foi a mais afetada pelo regime militar, restando-lhe esperar pela divisão do bolo (que nunca chegou). Qualquer reação seria revidada com a mais severa repressão (SD13); tudo em prol da segurança nacional, segundo o discurso militar.

\section{Considerações finais}

A partir deste estudo, foi possível identificar e compreender o funcionamento das estratégias argumentativas usadas no discurso militar, a partir dos AIs, para convencer os brasileiros da necessidade de ruptura da ordem institucional na ação militar de 31 de março 1964.

Através da análise das principais estratégias, materializadas em uma rede de memória constituída por dizeres que circularam nos cinco primeiros anos do regime (1964-69), foi possível observar 
V. $10(2)$

1-19

maio-ago

2020

que, ao longo desses anos, o Estado militar foi ressignificando o seu discurso, deixando marcas e pistas que possibilitaram acompanhar o avanço da resistência ao regime e, por conseguinte, o crescimento do autoritarismo estatal.

Assim, chegamos ao cerne de uma discursividade fincada há um século no imaginário brasileiro. Trata-se de uma rede de sentidos que parece adormecer durante um tempo considerável, mas que desperta em algum momento do Estado moderno, a partir do qual o capitalismo se desenvolveu e se movimenta para alcançar os seus objetivos, a exemplo do que acontece no mundo atual, em especial, no Brasil, atualizando uma memória atravessada de autoritarismo, que se reflete na linguagem.

Nesse sentido, para finalizar este estudo, é importante destacar que um período tão tenebroso da história brasileira como foi a ditadura militar não deve ser visto como um acontecimento estático, situado no passado, mas como um evento que faz parte da processualidade histórica, sob a determinação de fatores externos, a partir dos quais são construídas as estratégias argumentativas a fim de persuadir a massa a endossar ou repudiar algo. Espera-se que o estudo tenha contribuído para isso.

\section{Referências}

ACHARD, P. et al. Papel da memória. Tradução de José Horta Nunes. 4. ed. Campinas/SP: Pontes Editores, 2015.

ALTHUSSER, L. Aparelhos ideológicos de Estado: nota sobre os aparelhos ideológicos de Estado (AIE). 2. ed. Tradução de Walter José Evangelista e Maria Laura Viveiros de Castro. Rio de Janeiro: Graal, 1985.

BRASIL. Atos Institucionais. Disponível em: <http://www4.planalto.gov.br/ legislacao/legislacao-historica/atos-institucionais>. Acesso em: 21 de abril 2019.

COURTINE, J.-J. Análise do discurso político: o discurso comunista endereçado aos cristãos. Tradução de Patrícia Chittoni Ramos Reuillard. São Carlos/SP: EduFSCar, 2009.

FIORIN, J. L. Argumentação. São Paulo: Contexto, 2016.

INDURSKY, F. A fala dos quartéis e as outras vozes. 2. ed. Campinas/SP: Unicamp, 2013.

NARVÁEZ, M. D. La nueva retórica de Chaïm Perelman como teoría de la racionalidad práctica. Colombia: Eidos, n. 30, 2019. p. 104-129. 
NETTO, J. P. Pequena história da ditadura brasileira (1964-1985). São Paulo: Cortez, 2014.

ORLANDI, E. Análise de discurso: princípios e procedimentos. 10. ed. Campinas/SP: Pontes Editores, 2012a.

ORLANDI, E. As formas do silêncio. 6. ed. Campinas, SP: Editora da UNICAMP, 2007.

ORLANDI, E. Interpretação. Autoria, leitura e efeitos do trabalho simbólico. 6. ed. Campinas, SP: Pontes Editores, 2012b.

PÊCHEUX, M. Semântica e discurso: uma crítica à afirmação do óbvio. Campinas: Ed. Unicamp, 1988.

PERELMAN, C. Argumentação. Enciclopédia Einaudi. Lisboa: Imprensa Nacional-Casa da Moeda, 1987. v. 11.

PERELMAN, C.; OLBRECHTS-TYTECA, L. Tratado de argumentação: a nova retórica. Tradução de Maria Ermantina de Almeida Prado Galvão. São Paulo: Martins Fontes, 2005.

PLANTIN, C. Analyse et critique du discours argumentatif. In: KOREN, R.; AMOSSY, R. (Orgs.) Après Perelman: quelles politiques pour les nouvelles rhétoriques? Paris: L'Harmattan, 2002. p. 229-263.

VITALE, Alejandra. ¿Cómo pudo suceder? Prensa escrita y golpismo en la Argentina (1930-1976). Buenos Aires: Eudeba, 2015. 